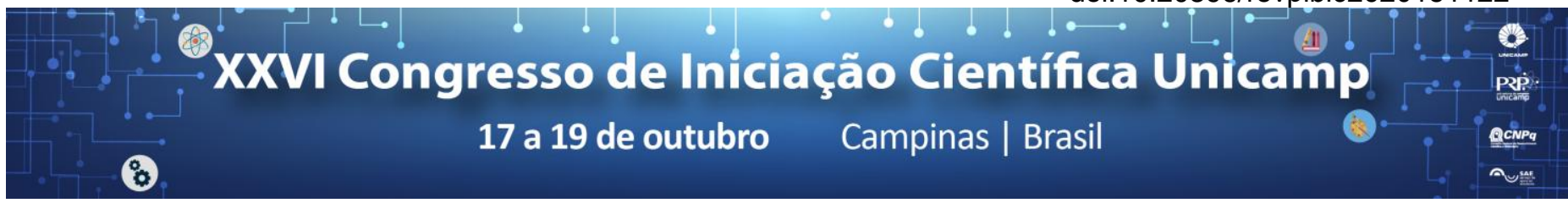

\title{
ANÁLISE DO DESEMPENHO DE ATLETA DE 400 METROS COM BARREIRAS POR MEIO DE SISTEMA DE DISTRIBUIÇÃO DE PRESSÃO PLANTAR
}

\author{
Autores: Paulo H. P. Rodrigues, Karine J. Sarro, Sanderley C. Parrela, Luis Viveiros, Ricardo M. L. Barros
}

\section{Resumo}

Esta pesquisa teve como objetivo desenvolver uma metodologia para análise da distribuição de pressão plantar na pisada de corredores da prova de 400 metros com barreiras, registrado pelo sistema Pedar-X (Novel, Alemanha) por meio de palminhas. A literatura cientifica referente à distribuição de pressão plantar na pisada de corredores de $400 \mathrm{~m}$ com barreiras ainda é restrita, sendo necessários maiores estudos para está preparação nos atletas de alto rendimento.

Palavras-chave: Biomecânica, Atletismo, 400m com barreiras.

\section{Introdução}

A corrida de velocidade é altamente complexa onde atleta e treinadores buscam progresso no desempenho desportivo (MIDGLEY, 2006) ${ }^{1}$. Com o avanço da tecnologia, a avaliação biomecânica tornou-se uma ferramenta importante de auxilio para obtenção dos resultados no esporte de alto rendimento.

Dessa forma, é necessário o desenvolvimento de metodologias específicas para análise do desempenho e das características individuais dos atletas.

O objetivo desse trabalho foi desenvolver uma metodologia para análise da distribuição de pressão plantar na pisada de corredores da prova de 400 metros com barreiras.

\section{Resultados e Discussão}

Utilizou-se o sistema Pedar-X (Novel, Alemanha) para medir a distribuição de pressão plantar internamente ao calçado por meio de palminhas instrumentadas durante uma prova de $400 \mathrm{~m}$ com barreira. O sistema fornece dados de distribuição de pressão plantar em cada um dos pés do atleta, a $100 \mathrm{~Hz}$ de frequência de amostragem em 96 sensores distribuídos no interior de cada palmilha.

A Figura 1 apresenta os resultados verificados de tempo de voo, o tempo de apoio ao solo (pista), o tempo e velocidades médias entre as barreiras.

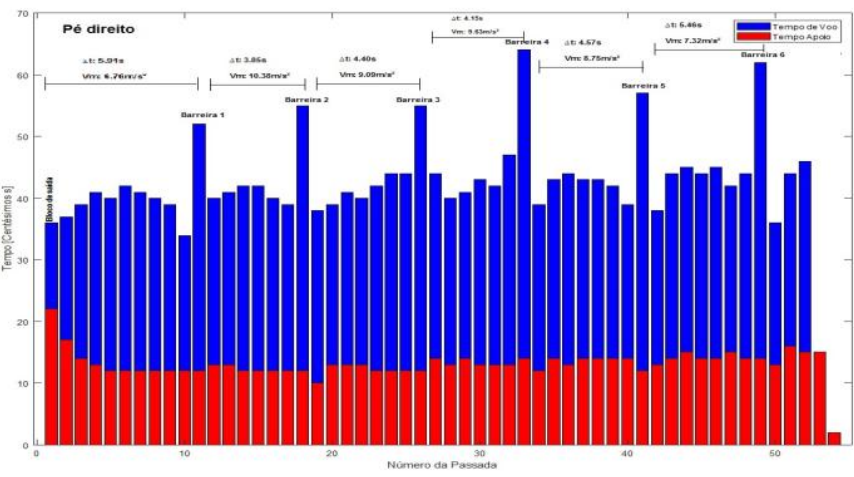

Figura 1. Desempenho do atleta na corrida.

É possível identificar na figura um conjunto de variáveis relevantes para a análise da performance do atleta. O tempo de apoio e voo em cada passada informam se o atleta manteve o ritmo durante a prova e como se comportou em cada fase da prova. Os valores de distribuição de pressão permitem saber como se deu cada pisada.

\section{Conclusões}

Dessa forma concluímos que a metodologia mostrou-se viável para verificar tanto tempos parciais como a distribuição de pressão plantar durante a corrida do atleta do alto rendimento. Outros estudos são necessários com outros atletas para verificarmos a reprodutibilidade dos dados, bem como devemos otimizar a fixação do equipamento ao atleta para minimizar o desconforto e o risco de perda de dados.

\footnotetext{
${ }^{1}$ MIDGLEY, Adrian W.; MCNAUGHTON, Lars R.; WILKINSON, Michael. Is there an optimal training intensity for enhancing the maximal oxygen uptake of distance runners? - empirical research findings, current opinions, physiological rationale and practical recommendations. Sports Medicine, v. 36 , n. 2, p. $117-132,2006$
} 